\title{
Presença de Sarcocysits spp. em marsupiais da espécie Didelphis albiventris na região sul do estado do Rio Grande do Sul, Brasil
}

\section{Presence of Sarcocystis spp. in opossums (Didelphis albiventris) in southern state Rio Grande do Sul, Brazil}

\author{
Luciana Araujo Lins, ${ }^{*}$ Lorena Soares Feijó, ${ }^{* *}$ Friedrich Frey Júnior, ${ }^{* \star *}$ \\ Cristina Gomes Zambrano, ${ }^{* *}$ Maria Elizabeth Aires Berne, ${ }^{* * *}$ Carlos Eduardo Wayne Nogueira ${ }^{* *}$
}

\begin{abstract}
Resumo
Este estudo avaliou o grau de infecção por Sarcocystis spp. em marsupiais do gênero Didelphis spp., conhecidos popularmente por gambás, no município de Bagé, na região sul do estado do Rio Grande do Sul (RS). Este parasito é o agente causador da Mieloencefalite Protozoária Equina (MEP), sendo que neste município estão localizados importantes criatórios de cavalos Puro-Sangue Inglês, demonstrando a importância deste estudo na região. O gambá atua como hospedeiro definitivo do parasito e elimina oocistos juntamente com as fezes. Os equinos infectam-se ao ingerir alimentos contaminados por fezes de gambás. Para o estudo, foram analisados 19 marsupiais da espécie Didelphis albiventris. Foram realizadas raspagens das três secções do intestino delgado dos gambás para avaliação de lesões macroscópicas e histopatológicas, como também para o isolamento e identificação de Sarcocystis spp. Na avaliação histopatológica, observou-se a presença de células inflamatórias, infiltrado de eosinófilos e áreas hemorrágicas, caracterizando enterite. Nos 19 (100\%) animais necropsiados e examinados, foi observada a presença de Sarcocystis spp., e em um (5,3\%) animal foi isolado Sarcocystis neurona.
\end{abstract}

Palavras-chave: Sarcocystis spp., Didelphis spp., MEP, equinos.

\begin{abstract}
This study evaluates the Sarcocystis spp. infection grade in Didelphis genus marsupials, popularly know as opossums, in southern state Rio Grande do Sul-Brazil. This parasite is the causative agent of Equine Protozoal Myeloencephalitis (EPM), and in this region are localized several important Thoroughbred stud farms, showing the importance of this study in the region. The opossum acts as the definitive host for the parasite and eliminates oocysts with its feces. The horses are infected when ingests food contaminated with opossums feces. For this study, were analyzed 19 marsupials Dide/phis albiventris species. Scratching from the three portions of the small intestine of the opossums was made to evaluate macroscopic and histopathologic lesions, as well as the isolation and identification of Sarcocystis spp. The histopathological evaluation showed inflammatory cells, eosinophil's infiltrate and hemorrhagic areas, characterizing enteritis. Nineteen animals (100.0\%) necropsied and examined were showed Sarcocystis spp presence, and in 1 (5.3\%) animal was isolated Sarcocystis neurona.
\end{abstract}

Keywords: Sarcocystis spp., Didelphis spp., EPM, horse.

\section{Introdução}

O estudo sobre Sarcocystis neurona, protozoário que utiliza marsupiais do gênero Didelphis como hospedeiro definitivo, tem recebido muita atenção, buscando esclarecer a associação deste agente com a Mieloencefalite Protozoária Equina (MEP). Esta enfermidade é causadora de grandes prejuízos para a equinocultura do estado do Rio Grande do
Sul (RS), principalmente no município de Bagé, que é um importante polo de criatórios da raça Puro-Sangue Inglês (PSI).

Os marsupiais do gênero Didelphis, conhecidos popularmente por gambás, possuem três espécies descritas: $D$. albiventris, $D$. marsupialis e $D$. virginiana. $D$. albiventris é encontrado nas regiões sul e sudeste do Brasil, $D$. marsupialis

* Faculdade de Veterinária - Universidade da Região da Campanha - Campus Bagé. Rua Valdomiro Domingues, no 85, apto 101. Bairro São Jorge. Bagé-RS. CEP 96408-640.nogueira@ufpel.edu.br/lucianaalins@yahoo.com.br

** Departamento de Clínicas Veterinária - Faculdade de Veterinária - Universidade Federal de Pelotas. Campus Universitário s/no - Caixa Postal 354. CEP 96010-900

*** Haras Santa Maria de Araras. Rua Flores da Cunha no 53, sala 31, Ed. Teorema, bairro Centro, Bagé-RS. CEP 96400350. ffreyjunior@yahoo.com.br

**** Departamento de Parasitologia - Instituto de Biologia - Universidade Federal de Pelotas. Campus Universitário s/no - Caixa Postal 354 . CEP 96010-900. bernemea@gmail.com

Autor para correspondência: Luciana Araujo Lins. Rua Quinze de Novembro, № 1550, Bairro Centro, Pelotas-RS. CEP $96015-000$. 
nas regiões sudeste e centro-oeste (Lange e Jablonski, 1998) e D. virginiana é habitante de países da América do Norte (Whitaker, 1994).

O ciclo evolutivo de protozoários do gênero Sarcocystis no hospedeiro definitivo inicia com a ingestão de cistos presentes nos músculos do hospedeiro intermediário. Espécies de Sarcocystis formariam cistos na musculatura de aves, hospedeiro intermediário, os quais seriam ingeridos pelos gambás (Dubey et al., 1997). Estes cistos desencistam-se no intestino delgado, iniciando uma reprodução sexuada que dará origem aos oocistos, liberados com as fezes de Didelphis spp. no ambiente. Aves e cavalos infectam-se pela ingestão de oocistos presente no alimento ou na água. A infecção no cavalo progride até a fase de meronte, fase esta não infecciosa, tornando o cavalo geralmente incapaz de disseminar a doença para outros animais (Mackay, 1997). Em estudo recente, Mullaney et al. (2005) observaram que o cavalo pode atuar também como hospedeiro intermediário, o que tornaria possível a contaminação de outros animais a partir da ingestão de tecidos contaminados dos equinos.

Em criatórios de cavalos é comum a presença de gambás, principalmente no seu período reprodutivo, que se estende de maio a janeiro (Lange e Jablonski, 1998), coincidindo com a época em que as fêmeas vão em busca de alimentos para os filhotes. Por possuir hábitos sinantrópicos, o gambá aproxima-se das instalações em busca de alimentos, oportunidade em que acaba por contaminar ração e/ou água com oocistos e/ou esporocistos de Sarcocystis eliminados em suas fezes (Foreman, 2005).

O objetivo deste estudo foi detectar a presença de Sarcocystis spp. em gambás do gênero Didelphis no município de BagéRS, através de estudos patológicos, histopatológicos e isolamento do agente.

\section{Material e métodos}

Foram utilizados marsupiais da espécie Didelphis albiventris, de um universo de animais recolhidos mortos em acidentes nas estradas periféricas a propriedades da região de Bagé-RS. Após recolhidos, os gambás foram identificados de acordo com suas características morfológicas, baseado na descrição de Silva (1984) e foram submetidos à necropsia, onde foi retirado o trato digestório e este avaliado quanto a sua integridade. Os animais que apresentaram os tecidos do trato digestório em fase de autólise foram descartados.

Os tratos digestórios foram separados por segmentos: estômago, intestino delgado, ceco, cólon e reto, e o material foi remetido ao Laboratório de Parasitologia, no Departamento de Microbiologia e Parasitologia, Instituto de Biologia da Universidade Federal de Pelotas (UFPel), para a avaliação de lesões macroscópicas na mucosa. Segmentos das três porções do intestino delgado foram fixadas em parafina e corados pelo método de Hematoxilina-eosina, sendo estes analisados por microscopia óptica para pesquisa de lesões histológicas. Este procedimento foi realizado no Laboratório Regional de Diagnóstico da Faculdade de Veterinária da UFPel.
O isolamento de esporocistos de Sarcocystis spp. foi realizado adequando-se a técnica descrita por Dubey et al. (1989). Após a retirada do excesso de conteúdo, foi realizada uma leve raspagem da mucosa intestinal, sendo este material colocado sobre uma lâmina e avaliado por microscopia óptica, utilizando microscópio Olympus ${ }^{\circledR}$ CX21 em aumento de 40x para o exame direto do esporocisto.

Para a identificação de $S$. neurona, amostras de raspados de cada porção do intestino delgado foram coletadas, sendo o material devidamente processado e armazenado em solução salina isotônica com tampão fosfatado (PBS) e antibiótico. Estas amostras foram enviadas para Beltsville, Maryland, Estados Unidos (EUA), onde os esporocistos foram bioanalisados em camundongos $\mathrm{KO}$ (imunossuprimidos por inoculação com gama interferon BALB/c-Inf- $\gamma$ ), como descrito por Dubey et al. (2000b, 2002).

\section{Resultados e discussão}

Do total de animais recolhidos, 19 apresentaram integridade do trato digestório, sendo submetidos à avaliação histopatológica. Destes, 12 eram fêmeas e sete eram machos, sendo todos da espécie Didelphis albiventris.

As lesões macroscópicas observadas no intestino delgado dos gambás necropsiados foram estrias hemorrágicas, conteúdo intestinal levemente sanguinolento, edema, hemorragia difusa caracterizando sinais de enterite, além da presença de células inflamatórias e infiltrado de eosinófilos.

$\mathrm{Na}$ avaliação histopatológica em todas as amostras observou-se a presença de células inflamatórias, como neutrófilos e macrófagos, congestão, células necróticas, infiltrado de eosinófilos, o que demonstra uma enterite multifocal eosinofílica discreta. Um animal apresentou também micro-abscessos na mucosa e submucosa do intestino delgado. $\mathrm{Na}$ literatura, nenhum trabalho foi realizado até o presente momento sobre lesões histopatológicas causadas por Sarcocystis spp. no intestino delgado e alterações hemorrágicas nos hospedeiros definitivos.

Os 19 animais (100\%) avaliados demonstraram a presença de Sarcocystis spp. em raspados da mucosa intestinal avaliados por microscopia óptica. Isolados de Sarcocystis spp. em Didelphis spp. revelaram alterações macroscópicas no intestino delgado, sendo observada lesão filamentosa com pigmentação branca na mucosa e grandes áreas hemorrágicas. Na observação microscópica do conteúdo intestinal foi visualizada uma grande quantidade de esporocistos e estes geralmente encontravam-se em maior número nos terços médio e final deste órgão, da mesma forma que descreveu Dubey et al., em 1991.

Foi confirmada a presença de $S$. neurona em uma das amostras, a identificação das espécies de Sarcocystis é baseada em características moleculares, biológicas e genéticas. Nos Estados Unidos foi isolado S. neurona em $15 \%$ de $D$. virginiana submetidos à raspagem intestinal (Elsheikha et al., 2004). Nos EUA já foi identificado S. neurona e S. speeri em D. marsupialis (Dubey et al., 2000a). No Brasil, $D$. marsupialis é o hospedeiro definitivo de $S$. falcatula (Dubey et al., 2000a) e de $S$. speeri, e em D. albiventris capturados 
na cidade de São Paulo foi identificado $S$. neurona (Dubey et al., 2001).

Foi demonstrado que, no Brasil, os cavalos apresentam alta taxa de soropositividade para $S$. neurona, caracterizando a alta exposição ao agente (Hoane et al., 2006). Neste estudo foi isolado Sarcocystis spp. em Didelphis albiventris no sul do Rio Grande do Sul, sendo esta região uma referência na

\section{Referências}

DUBEY, J.P.; KERBER, C.E.; LINDSAY, D.A.; KASAN, N.; PENA, H.F.T. The South American opossum, Didelphis marsupialis, from Brazil as another definitive host for Sarcocystis speeri (Dubey and Lindsay, 1999). Parasitology, Cambridge, v. 121, n. 6, p. 589-594, dez. 2000 a. DUBEY, J.P.; SPEER, C.A.; BOWMAN, D.D.; HORTON, K.M.; VENTURINI, C.; VENTURINI, L. Experimental transmission of Sarcocystis speeri (Dubey \& Lindsay, 1999) from the South American opossum (Didelphis albiventris) to the North American opossum (Didelphis virginiana). The Journal of Parasitology, Lincoln, v. 86, n. 3, p. 624-627, Jun. 2000b.

DUBEY, J.P.; BLACK, S.S.; RICKARD, L.G.; ROSENTHAL, B.M.; LINDSAY, D.S.; SHEN, S.K.; KWOK, O.C.H.; HURST, G.; RASHMIRRAVEN, A. Prevalence of Sarcocystis neurona sporocysts in opossums (Didelphis virginiana) from rural Mississipi. Veterinary Parasitology, Amsterdam, v. 95, n. 2-4, p. 283-293, Fev. 2001.

DUBEY, J.P.; SAVILLE, W.J.; SREEKUMAR, C.; SHEN, S.K.; LINDSAY, D.S.; PENA, H.F.; VIANNA, M.C.; GENNARI, S.M.; REED, S.M. Effects of hight temperature and disinfectants on the viability of Sarcocystis neurona sporocysts. The Journal of Parasitology, Lincoln, v. 88, n. 6, p. 1252-1254, Dez. 2002.

DUBEY, J.P.; DAVIS, S.W.; SPEER, C.A. Sarcocystis neurona n. sp. (Protozoa: apicomplexa), the etiologic agent of equine protozoal myeloencephalitis. The Journal of Parasitology, Lincoln, v. 77, p. 212-218, 1991.

DUBEY, J.P.; GRANSTROM, D.E.; GAJADHAR, A.; WILLIAMS, S.A. McCRILLIS, S.A.; STAMPER, S.; LANGEMEIER, J.L. Experimental induction of equine protozoal myeloencephalitis in horses using Sarcocystis sp sporocystis from the opossum (Didelphis virginiana). Veterinary Parasitology, Amsterdam, v. 68, n. 3, p. 199-213, Fev. 1997. criação de cavalos PSI, o que torna importante a avaliação de medidas de prevenção para a MEP.

\section{Conclusão}

Este estudo detectou a presença de Sarcocystis spp. em gambás da espécie Didelphis albiventris na região de Bagé, RS.

DUBEY, J.P.; SPEER, C.A.; FAYER, R. Sarcocystis of animals and man. Boca Raton: CRC Press, 1989.

ELSHEIKHA, H.M.; MANSFIELD, L.S. Molecular typing of Sarcocystis neurona: Current status and future trends. Veterinary Parasitology, Fort Collins, v. 149, p. 43-55, 2007.

FOREMAN, J.H. Losing control: Nutritional-related diseases of the central nervous system. Kentucky Equine Research Proceedings Advances in Equine Nutrition, Versailles, v. 3, p. 97-114, jan./dez. 2005.

HOANE, J.S.; GENNARI, S.M.; DUBEY, J.P.; RIBEIRO, M.G.; BORGES, A.S.; YAI, L.E.O.; AGUIAR, D.M.; CAVALCANTE, G.T.; BONESI, G.L.; HOWE, D.K. Prevalence of Sarcocystis neurona and Neospora spp. infection in horses from Brazil based on presence of serum antibodies to parasite surface antigen. Veterinary Parasitology, Fort Collins, v. 136, p. 155-159, 2006.

LANGE, R.B.; JABLONKSKI, E.F. Estudos de Biologia, v. 43, Número especial, Brasil. Pontifícia Universidade Católica do Paraná, 1998, $224 \mathrm{p}$.

MACKAY, R.J. Equine protozoal myeloencephalitis. Veterinary Clinics of North America: Equine Practice, Orlando, v. 13, n. 1, p. 79-96, abr. 1997.

MULLANEY, T; MURPHY, A.J.; KIUPEL, M.; BELL, J.B.; ROSSANO, M.G.; MANSFIELD, L.S. Evidence to support horses as natural intermediate hosts for Sarcocystis neurona. Veterinary Parasitology, v. 133, p. 27-36, 2005.

SILVA, F. Mamíferos silvestres do Rio Grande do Sul. Fundação Zoobotânica do Rio Grande do Sul. Porto Alegre, 1984. 246 p.

WHITAKER, J.J. National Audubon Society- Field Guide to North American Mammals. NovaYork: Chanticleer Inc., 1994, 273 p. 